\title{
AOR
}

Selected Papers of \#AolR2021:

The 22nd Annual Conference of the

Association of Internet Researchers

Virtual Event / 13-16 Oct 2021

\section{INTERNET GOVERNANCE FOR WHOM? CIVIL SOCIETY, REPRESENTATION, AND DIGITAL RIGHTS}

Rohan Grover

University of Southern California

\section{Introduction}

Internet governance institutions have generally embraced a multistakeholder approach which calls for consulting different types of stakeholders, notably states, the private sector, and civil society organizations (CSOs; Raymond \& DeNardis, 2015). However, the category of civil society is historically ill defined. Looking to understand how civil society is constructed in supranational institutions, Tjahja et al. (2021) developed a typology of CSOs included at the Internet Governance Forum (IGF) over time, and found that while civil society at the IGF is composed of diverse organizational models, in general CSOs are expected to be intermediaries that represent the interests of a community, and to validate internet governance institutional processes.

Given their crucial role in internet governance, how well do digital rights CSOs fulfill expectations of representation under multistakeholderism?

\section{Methodology}

I approached this question through a case study of the Internet Freedom Foundation (IFF), an Indian digital rights organization. IFF represents Indian interests in the internet governance and digital rights fields and is seen as a credible representative of Indian interests on the basis of its history of democratic public mobilization, especially through the Save The Internet (STI) campaign in 2016 which spawned the organization.

I brought together two approaches to assess how well IFF represents the Indian public. First, I characterized IFF's mechanisms of representation according to three strategies, defined by Fraussen and Halpin (2018), that interest groups use to achieve legitimacy. Second, I evaluated the quality of IFF's representation through the lens of equity and democratization, which I defined as inclusion of diverse socioeconomic identities, especially class, caste, and gender. This approach answers Alhassan and Chakravartty's (2011) call to scrutinize the independence of CSOs in the postcolonial 
context, where they are not inherently representative or neutral in part because CSOs do not necessarily represent interests that are distinct from the state.

Empirically, I examined IFF's public communications through its website, newsletter, event recordings and other YouTube videos, and social media accounts. Following a grounded theory approach, I reviewed these communication materials to identify themes in both what the organization asks of its audience and how it describes its relationship with its audience, in order to understand how IFF articulates and achieves representation.

\section{Findings}

IFF appears to select its agenda through a centralized process rather than consulting its supporters for input. This "logic of solidarity", in which the public is engaged as supporters and donors in solidarity with a cause or set of values articulated by the organization, contrasts with a "logic of representation" in which the public is invited to define organizational priorities by vocalizing their concerns (Fraussen and Halpin, 2018).

In addition, IFF claims to represent the general Indian public, but primarily mobilizes technology workers who differ from the general Indian public in important ways. Most notably, based on descriptions of its staff, board, and volunteers, IFF appears to primarily engage technologists, especially software engineers in India's startup industry. Looking at IFF's predecessor, the STI campaign, Prasad (2018) refers to a "recursive public" that re-engages technology workers in activism to shape the very technologies that bring them together. She argues that their politics align with a technocultural nationalism that seeks joint economic and technological power through digitally mediated neoliberal market opportunities. Therefore while IFF's supporters are citizens advocating for digital rights, they also represent a class of workers in an industry shaped by class, caste, and gender discrimination (Subramanian, 2019; Upadhya, 2016) and whose economic opportunities are uniquely intertwined with specific policy outcomes.

These findings provide evidence of a gap between the expectations of IFF according to multistakeholderism and the organization's community engagement strategies observed in the field. Tjahja's et al. (2021) finding that CSOs are meant to represent the interests of under-represented communities, rather than interests of CSOs themselves, suggests that internet governance institutions likely expect CSOs to enact strategies that resemble a logic of representation in order to authentically represent community-driven interests, compared to the logic of solidarity observed in IFF's public engagement. Moreover, these findings suggest that IFF may better represent a community of technology workers, rather than the entire Indian public, which is shaped by structural forces that reproduce socioeconomic inequities.

\section{Discussion}

This gap demonstrates the importance of evaluating representation through the lens of equity and democratization, as Alhassan and Chakravartty (2011) prescribe. However, 
on a global stage, equity and democratization must be defined to account for both national and international dynamics. For example, the STI campaign that spawned IFF is celebrated for countering digital colonialism between US-based Facebook and Indian activists (Kwet, 2019). Yet this perspective is not sufficient to characterize STI and its successor, IFF, as inherently equitable within the Indian context, as Prasad (2018) illuminates the reproduction of socioeconomic inequalities.

A comprehensive evaluation of equity and democratization, then, must account for both colonial dynamics across states and socioeconomic inequities within the postcolonial state. But without access to membership data, how can we evaluate CSOs' community representation strategies? Fraussen and Halpin's (2018) framework is valuable for identifying mechanisms of representation for the purpose of signaling legitimacy to (presumably domestic) policymakers. However, when legitimacy is specifically tied to representation and especially by supranational actors, as in the case of internet governance, evaluating representation in digital-native CSOs should account for how engagement strategies intersect with both socioeconomic and technological inequities within the national context. For example, in the case of IFF, who is excluded from access to representation or engagement because of poor, contingent, or lack of internet connectivity? And who benefits from socioeconomic proximity to the recursive public mobilized by their campaigns?

These findings do not undermine the advocacy of IFF, which bravely contests the Indian state's authoritarian digital practices, but rather it offers a contribution to an emergent understanding of civil society's role in internet governance, grounded in a critique of representation and legitimacy in the postcolonial state. More textured and historically specific research about CSOs and their strategies of representation will expand our understanding of how whose voices are heard, and whose are still excluded, from supranational institutions and processes that shape internet governance and digital rights.

\section{References}

Alhassan, A., \& Chakravartty, P. (2011). Postcolonial media policy under the long shadow of empire. In R. Mansell \& M. Raboy (Eds.), The handbook of global media and communication policy (pp. 366-382). Wiley-Blackwell.

https://doi.org/10.1002/9781444395433.ch23

Fraussen, B., \& Halpin, D. (2018). How do interest groups legitimate their policy advocacy? Reconsidering linkage and internal democracy in times of digital disruption. Public Administration, 96(1), 23-35. https://doi.org/10.1111/padm.12364

Kwet, M. (2019). Digital colonialism: US empire and the new imperialism in the Global South. Race \& Class, 60(4), 3-26. https://doi.org/10.1177/0306396818823172

Prasad, R. (2018). Ascendant India, digital India: How net neutrality advocates defeated Facebook's Free Basics. Media, Culture \& Society, 40(3), 415-431. https://doi.org/10.1177/0163443717736117 
Raymond, M., \& DeNardis, L. (2015). Multistakeholderism: Anatomy of an inchoate global institution. International Theory, 7(3), 572-616.

https://doi.org/10.1017/S1752971915000081

Subramanian, A. (2019). The caste of merit: Engineering education in India. Harvard University Press.

Tjahja, N., Meyer, T., \& Shahin, J. (2021). What is civil society and who represents civil society at the IGF? An analysis of civil society typologies in internet governance. Telecommunications Policy, 45(6). https://doi.org/10.1016/j.telpol.2021.102141

Upadhya, C. (2016). Reengineering India: Work, capital, and class in an offshore economy. Oxford University Press.

https://doi.org/10.1093/acprof:oso/9780199461486.001.0001 